\title{
ESTABILIDAD Y CAPACIDAD INHIBITORIA DEL BACTERIÓFAGO ФRSP, AGENTE POTENCIAL PARA EL BIOCONTROL DE Ralstonia solanacearum
}

\author{
STABILITY AND INHIBITORY CAPACITY OF BACTERIOPHAGE ФRSP, \\ A POTENTIAL AGENT FOR THE BIOCONTROL OF Ralstonia solanacearum
}

\author{
Jesús Hernández-Romano*', Luz A. Mastache-Estrada', D. Alfredo Molina-Sánchez', \\ Rafael Serrano-Plancarte', Christopher Peña-Barrera', Ma. Inés Chávez-Bejar', \\ Nadia Romero-Martínez ${ }^{1}$ y A. Neri Lecona-Valera ${ }^{2}$
}

1Universidad Politécnica del Estado de Morelos, Jiutepec, Morelos, México. ${ }^{2}$ Instituto Nacional de Salud Pública, Centro de Investigación Sobre Enfermedades Infecciosas, Cuernavaca, Morelos, México.

*Autor para correspondencia (jhernandez@upemor.edu.mx)

\section{RESUMEN}

La marchitez bacteriana del tomate causada por Ralstonia solanacearum es un problema recurrente en el estado de Morelos y otras partes de México y el mundo. Los métodos actuales para el control de este fitopatógeno bacteriano se basan en el uso de antibióticos que promueven la selección de bacterias resistentes y en agroquímicos que son tóxicos para los humanos, las plantas y el medio ambiente en general. Estos métodos de control degradan la calidad de los suelos al eliminar gran parte de la microbiota normal debido a su amplio espectro de acción. Esta situación pone de manifiesto la necesidad de desarrollar métodos de control alternativos que estén alineados con el desarrollo sostenible de la agricultura. Los bacteriófagos líticos ofrecen una alternativa de control debido a su alta especificidad, baja toxicidad y capacidad de auto-amplificación. En este trabajo se reporta el aislamiento, la estabilidad y la capacidad inhibitoria del bacteriófago $\Phi R S P$, infectivo para $R$. solanacearum. Este bacteriófago pertenece a la familia Mioviridae y genera placas de lisis de aproximadamente $0.5 \mathrm{~cm}$ de diámetro después de $24 \mathrm{~h}$ de incubación, que continúan aumentando su tamaño con el tiempo. Este bacteriófago tiene la capacidad de aclarar los cultivos líquidos de $R$. solanacearum a muy pocas multiplicidades de infección y es estable en la solución nutritiva utilizada para el cultivo de tomate hidropónico, en un rango de $\mathrm{pH}$ de 4 a 11; sin embargo, es inestable en agua ultrapura. Los resultados muestran que el bacteriófago $\Phi$ RSP presenta características que lo señalan como un buen candidato para ser utilizado como agente de control biológico contra la marchitez bacteriana causada por $R$. solanacearum.

Palabras clave: Ralstonia solanacearum, marchitez bacteriana, bacteriófagos, biocontrol, lisis, estabilidad.

\section{SUMMARY}

Bacterial wilt of tomato caused by Ralstonia solanacearum is a recurring problem in the state of Morelos and other parts of Mexico and the world. Current methods for the control of this bacterial phytopathogen are based on the use of antibiotics that promote the selection of resistant bacteria, and on agrochemicals that are toxic to humans, plants and the environment in general. These control methods degrade the quality of soils by eliminating much of the normal microbiota due to their broad spectrum of action. This situation highlights the need to develop alternative control methods that are aligned with the sustainable development of agriculture. The strict lytic bacteriophages offer an alternative of control due to their high specificity, low toxicity and capacity of auto-amplification. In this paper, the isolation, stability and inhibitory capacity of bacteriophage $\Phi R S P$, infective for $R$. solanacearum are reported. This bacteriophage belongs to the family
Mioviridae and generates lysis plates of approximately $0.5 \mathrm{~cm}$ in diameter after $24 \mathrm{~h}$ of incubation, which continue to increase their size over time. This bacteriophage has the ability to clarify liquid cultures of $R$. solanacearum at very low multiplicities of infection and is stable in the nutrient solution used for the cultivation of hydroponic tomato, in a pH range from 4 to 11 ; however, it is unstable in ultrapure water. Results show that the bacteriophage QRSP presents characteristics that point it as a good candidate to be used as a biocontrol agent against bacterial wilt caused by $R$. solanacearum.

Index words: Ralstonia solanacearum, bacterial wilt, bacteriophages, biocontrol, lysis, stability.

\section{INTRODUCCIÓN}

Ralstonia solanacearum (Smith, 1896) Yabuuchi et al., 1996 emend. Safni et al., 2014 es uno de los fitopatógenos bacterianos de mayor importancia a nivel mundial (Mansfield et al., 2012). En Morelos y otras partes de México ha causado pérdidas a los productores de tomate (Solanum lycopersicum) (Hernández-Romano et al., 2012; Perea et al., 2011), así como a productores de plátano (Musa × paradisiaca) (Obrador-Sánchez et al., 2017). Tiene un amplio rango de hospederos que infectan a más de 200 especies vegetales de al menos 44 familias taxonómicas (Hayward, 1991). La infección por R. solanacearum causa marchitez, que con frecuencia culmina con la muerte de la planta de una a tres semanas posteriores al inicio de los síntomas.

El tratamiento para combatir esta enfermedad se basa en antibióticos como oxitetraciclina, gentamicina y estreptomicina (McManus et al., 2002; Stockwell y Duffy, 2012). Este método de control no está alineado con el desarrollo sustentable de la agricultura, ya que elimina indiscriminadamente bacterias del suelo, muchas de ellas benéficas para el desarrollo vegetal (Falkowski et al., 2008; Sharma et al., 2013). La aplicación de antibióticos favorece la selección de bacterias portadoras de genes de resistencia que reducen la eficacia de estos compuestos y potencialmente contribuyen al problema 
de la resistencia antimicrobiana en el tratamiento clínico de las enfermedades bacterianas humanas (Economou y Gousia, 2015; López et al., 2009; Thiele-Bruhn, 2003; You y Silbergeld, 2014). Esta situación resalta la necesidad de desarrollar nuevas estrategias de control, no agresivas para el ambiente ni para la salud humana y que contribuyan a mejorar la productividad de los cultivos agrícolas (Sundin et al., 2016).

Los bacteriófagos, virus que infectan bacterias, representan una alternativa para el control de fitopatógenos bacterianos (Frampton et al., 2012; Jones et al., 2007; Żaczek et al., 2015). Existen reportes de la efectividad de estos agentes para combatir la marchitez bacteriana del tomate (Bae et al., 2012; Bhunchoth et al., 2015; Fujiwara et al., 2011; Kalpage y De Costa, 2014); sin embargo, es importante analizar cada nuevo aislamiento, ya que algunos bacteriófagos pueden modificar la virulencia de la bacteria hacia la planta (Addy et al., 2012a; b; c).

Como parte del análisis de los bacteriófagos se evalúan sus características fisicoquímicas, biológicas y genómicas. El análisis fisicoquímico evalúa su estabilidad frente a cambios en el pH, temperatura, composición salina del medio, etc. Con el análisis biológico se evalúa la capacidad para inhibir la proliferación bacteriana, el rango de hospederos o la modificación de la virulencia bacteriana. El análisis genómico permite identificar genes asociados con comportamientos lítico o temperado y detectar genes que puedan modificar la virulencia del hospedero (Jassim y Limoges, 2014).

El objetivo de este trabajo fue analizar características fisicoquímicas (estabilidad en soluciones con diferente composición salina a diferentes valores de $\mathrm{pH}$ ) y biológicas (capacidad inhibitoria hacia $R$. solanacearum) del bacteriófago ФRSP y determinar la presencia de propiedades que apoyen su utilidad como un agente potencial de biocontrol de la marchitez bacteriana causada por R. solanacearum.

\section{MATERIALES Y MÉTODOS}

\section{Cepa bacteriana y condiciones de crecimiento}

La cepa de $R$. solanacearum se aisló en Coatlán del Río, Morelos (Hernández-Romano et al., 2012). Se cultivó en NBY (peptona de caseína, $5 \mathrm{~g} \mathrm{~L}^{-1}$; extracto de carne, 3 $\mathrm{g} \mathrm{L}^{-1}$; extracto de levadura, $2 \mathrm{~g} \mathrm{~L}^{-1} ; \mathrm{K}_{2} \mathrm{HPO}_{4}$ (anhidro), 2.0 $\mathrm{g} \mathrm{L}^{-1} ; \mathrm{KH}_{2} \mathrm{PO}_{4}, 0.5 \mathrm{~g} \mathrm{~L}^{-1}$; sacarosa, $25 \mathrm{~g} \mathrm{~L}^{-1} ; \mathrm{MgSO}_{4} \cdot 7 \mathrm{H}_{2} \mathrm{O}$, $0.001 \mathrm{M})$ (Evtushenko y Takeuchi, 2006) a $30 \pm 2{ }^{\circ} \mathrm{C}$ y en agitación (250 rpm) por 24 h bajo condiciones aerobias en un agitador (Innova® 44, New Brunswick, Canadá).

\section{Aislamiento del bacteriófago $\Phi \mathrm{RSP}$}

El bacteriófago $\Phi R S P$ se aisló de agua de cultivos de tomate infectados por $R$. solanacearum. Se mezclaron 50 $\mathrm{mL}$ de la muestra de agua a analizar con $20 \mathrm{~mL}$ de cultivo líquido de $R$. solanacearum de 12 a 16 h de crecimiento en NBY. La mezcla se incubó por 16 h en condiciones aerobias, en agitación a 200 rpm y 30 C. La detección de bacteriófagos se hizo tomando una alícuota de $1 \mathrm{~mL}$, la cual se centrifugó a 10,000 × g por 3 min; posteriormente, se filtró el sobrenadante con una membrana de $0.45 \mu \mathrm{m}$. Del filtrado se prepararon ocho diluciones decimales en las que se utilizó NBY estéril como diluyente. Se preparó una suspensión bacteriana tras mezclar $8 \mathrm{~mL}$ de NBY con agar suave (NBY con agar bacteriológico al $0.7 \%$ ) fundido y a $40^{\circ} \mathrm{C}$, con $50 \mu \mathrm{L}$ de un cultivo de $R$. solanacearum en NBY líquido con un máximo de 24 h de crecimiento.

La mezcla se vertió en una caja de Petri de $90 \times 15 \mathrm{~mm}$ y se dejó solidificar por $15 \mathrm{~min}$. En diferentes secciones de la caja de Petri se colocó una alícuota de $10 \mu \mathrm{L}$ de cada una de las diluciones de la muestra filtrada, se dejó secar el líquido sin extenderlo, se incubó a $30^{\circ} \mathrm{C}$ por 24 h y se observó la presencia de placas de lisis. El fago se purificó tomando una placa de lisis y colocándola en un cultivo líquido de $R$. solanacearum con 16 a 24 h de crecimiento, se incubó por 24 h y centrifugó a 10,000 × g por 3 min. El sobrenadante se filtró en una membrana de $0.45 \mu \mathrm{m}$ y la concentración del bacteriófago se determinó como se explica en la siguiente sección.

\section{Titulación de las soluciones fágicas}

Para determinar la concentración de las soluciones fágicas se utilizó la técnica del doble agar (Kropinski et al., 2009) modificada. Se utilizaron tubos con $8 \mathrm{~mL}$ de NBY con agar suave a $40{ }^{\circ} \mathrm{C}$. Bajo condiciones de esterilidad, se prepararon ocho diluciones decimales de la solución fágica a titular, se tomaron $15 \mu \mathrm{L}$ de la misma y se diluyeron con $135 \mu \mathrm{L}$ de medio NBY estéril. A cada dilución se le adicionaron $50 \mu \mathrm{L}$ de un cultivo de $R$. solanacearum de 16 a $24 \mathrm{~h}$ de crecimiento, esta mezcla se colocó en el tubo con agar suave a $40^{\circ} \mathrm{C}$, se mezcló y el contenido se vertió en una caja de Petri que se dejó solidificar e incubar por $24 \mathrm{~h}$ a $30 \pm 2^{\circ} \mathrm{C}$. Se identificaron aquellas cajas que presentaron entre 30 y 150 placas de lisis (pfu's, "plate forming units") y se calculó el título aplicando la siguiente ecuación:

$$
\mathrm{pfu} \text { 's } / \mathrm{mL}=\frac{[(\text { Número de pfu's }) \times(\text { Factor de dilución }) \times 1000]}{[\text { volumen utilizado de la dilución en } \mu \mathrm{L}]}
$$

Cada titulación se hizo por triplicado. La titulación se consideró adecuada si era evidente el efecto de dilución y el coeficiente de variación era menor a $20 \%$. 


\section{Estabilidad del bacteriófago $\Phi$ RSP en diferentes soluciones acuosas}

La estabilidad se evaluó en los siguientes medios: 1) NBY, 2) buffer $\mathrm{SM}$ (Tris- $\mathrm{HCl}, 50 \mathrm{mM} ; \mathrm{NaCl}, 0.1 \mathrm{M}$; $\mathrm{MgSO}_{4} \cdot 7 \mathrm{H}_{2} \mathrm{O}, 8 \mathrm{mM}$; gelatina, $\left.0.002 \%\right)$, 3) solución de sulfatos y fosfatos $\left(\mathrm{K}_{2} \mathrm{SO}_{4}, 0.27 \mathrm{~g} \mathrm{~L}^{-1} ; \mathrm{MgSO}_{4} \cdot 7 \mathrm{H}_{2} \mathrm{O}, 0.44 \mathrm{~g}\right.$ $\left.\mathrm{L}^{-1} ; \mathrm{KH}_{2} \mathrm{PO}_{4^{\prime}} 0.14 \mathrm{gL}^{-1}\right)$ y 4) solución de sulfatos y fosfatos $5 \mathrm{X}\left(\mathrm{K}_{2} \mathrm{SO}_{4^{\prime}}, 1.35 \mathrm{~g} \mathrm{~L}^{-1} ; \mathrm{MgSO}_{4} \cdot 7 \mathrm{H}_{2} \mathrm{O}, 2.20 \mathrm{~g} \mathrm{~L}^{-1} ; \mathrm{KH}_{2} \mathrm{PO}_{4^{\prime}} 0.70\right.$ $\left.\mathrm{g} \mathrm{L}^{-1}\right)$. De cada una de estas soluciones, se tomaron $990 \mu \mathrm{L}$ y se mezclaron con $10 \mu \mathrm{L}$ de una solución del fago ФRSP con una concentración de $1 \times 10^{11} \mathrm{pfu}$ 's $/ \mathrm{mL}$ en medio NBY. A intervalos de aproximadamente una semana se determinó el título de cada solución. Estas evaluaciones se realizaron a temperatura ambiente y por triplicado.

\section{Microscopía electrónica}

Mediante una solución fágica con un título de $1 \times$ $10^{8} \mathrm{pfu}$ 's $/ \mathrm{mL}$ los bacteriófagos fueron sedimentados por centrifugación a 40,000 $\times g$ por 1 h. La pastilla se resuspendió en buffer SM. Diluciones de esta suspensión (1:10 y 1:50) se colocaron durante $3 \mathrm{~min}$ en rejillas cubiertas con Formvar-carbon e inmediatamente se eliminó el exceso. Las muestras se contrastaron por tinción negativa con acetato de uranilo 3 \% y se observaron en un microscopio electrónico de transmisión (JEOL 1011, JEOL, Inc., Peabody, MA, USA).

\section{Estabilidad del bacteriófago $\Phi$ RSP bajo diferentes condiciones de $\mathrm{pH}$}

Para evaluar la estabilidad del bacteriófago ФRSP a distintos valores de $\mathrm{pH}$, se seleccionó la solución en la que el bacteriófago presentó mayor estabilidad (solución de sulfatos y fosfatos $5 \mathrm{X}$ ) y en diferentes alícuotas se ajustó el $\mathrm{pH}$ a valores de 2.0 a 12.0, con incrementos de una unidad. A $1.0 \mathrm{~mL}$ de cada alícuota se le adicionaron $10 \mu \mathrm{L}$ de una solución del fago $\$$ RSP con una concentración de $1 \times 10^{11} \mathrm{pfu} / \mathrm{s} / \mathrm{mL}$. Se mezcló perfectamente por inversión y se dejó incubar $1 \mathrm{~h}$ a temperatura ambiente para después determinar el título fágico en cada solución. La estabilidad a cada valor de pH se evaluó por triplicado.

\section{Efecto del bacteriófago $\Phi$ RSP sobre el cultivo bacteriano en medio líquido}

Se preparó un cultivo líquido de $R$. solanacearum en medio NBY con 16 a 24 h de crecimiento. Se centrifugó y la pastilla se resuspendió en medio mineral con glucosa $\left[\left(\mathrm{NH}_{4}\right)_{2} \mathrm{SO}_{4^{\prime}} 0.060 \mathrm{~g} \mathrm{~L}^{-1} ; \mathrm{KNO}_{3^{\prime}} 0.38 \mathrm{~g} \mathrm{~L}^{-1} ; \mathrm{KH}_{2} \mathrm{PO}_{4^{\prime}} 0.50 \mathrm{~g} \mathrm{~L}^{-1} ;\right.$ $\mathrm{K}_{2} \mathrm{HPO}_{4}, 2.0 \mathrm{~g} \mathrm{~L}^{-1} ; \mathrm{MgSO}_{4} \cdot 7 \mathrm{H}_{2} \mathrm{O}, 2.25 \mathrm{~g} \mathrm{~L}^{-1} ; \mathrm{CaCl}_{2}, 0.02 \mathrm{~g} \mathrm{~L}^{-1}$; glucosa, $5.0 \mathrm{~g} \mathrm{~L}^{-1}$ y se ajustó a una densidad óptica de $0.370 \pm 0.001$ a $600 \mathrm{~nm}$. De esta suspensión bacteriana se utilizaron $250 \mu \mathrm{L}$ para inocular un reactor de $50 \mathrm{~mL}$ que contenía $24.75 \mathrm{~mL}$ de medio mineral con glucosa. Una vez inoculados con la bacteria, los reactores se colocaron en el sistema RTS-1C (Biosan, BS-010160-A02, Riga, Republic of Latvia) y se incubaron por $24 \mathrm{~h}$ a $30{ }^{\circ} \mathrm{C}$ y $2000 \mathrm{rpm}$, inoculando el fago $\Phi$ RSP $8 \mathrm{~h}$ después de la inoculación bacteriana, momento en el que se iniciaba el crecimiento exponencial de la curva de crecimiento bacteriano.

Para establecer la multiplicidad de infección (MOI, Multiplicity of infection) se determinó la concentración bacteriana en el biorreactor al momento de la inoculación fágica, que fue de $2 \times 10^{6} \mathrm{ufc} / \mathrm{mL}$. Con este dato y con el título de la solución fágica de trabajo $\left(2.3 \times 10^{9} \mathrm{pfu}\right.$ 's $\left./ \mathrm{mL}\right)$ se determinó el volumen de solución fágica a tomar para utilizar MOl's de $10^{-2}, 10^{-4}$ y $10^{-6}$. Cuando fue necesario, se prepararon diluciones de la solución fágica. En todas las cinéticas la densidad óptica se registró cada 15 minutos a 850 nm. Cada condición se evaluó por triplicado.

\section{RESULTADOS Y DISCUSIÓN}

\section{Morfología de bacteriófago $\Phi$ RSP}

El bacteriófago $\Phi$ RSP genera placas de lisis de 0.2 a 0.5 $\mathrm{cm}$ de diámetro después de $24 \mathrm{~h}$ de incubación y continúan creciendo mientras las condiciones de humedad en el medio sean adecuadas (Figura 1). La morfología de este bacteriófago es compatible con la de los miovirus, presenta una cabeza icosaédrica y una cola rígida que posee una vaina (Figura 1, flecha) y un tubo (Figura 1, punta de flecha), lo que concuerda con la descripción de Ackermann (2011)

El bacteriófago QRSP presenta una relativa facilidad para difundir en la capa de agar suave e infectar nuevas bacterias. Esta característica puede resultar conveniente para el biocontrol, pues sugiere que las características intrínsecas del fago le permiten difundir con facilidad, lo que incrementa su capacidad para encontrar y eventualmente destruir a células bacterianas de $R$. solanacearum, ya sea en el suelo o en sustratos de cultivos semi-hidropónicos; - bien, para actuar con efectividad en presencia de biopelículas (Abedon y Yin, 2009; Gallet et al., 2009; 2011).

\section{Estabilidad del bacteriófago $\Phi$ RSP en distintas soluciones}

El bacteriófago ФRSP fue estable en la solución de sulfatos y fosfatos, su estabilidad aumentó cuando la concentración de las sales se quintuplicó (Figura 2). En NBY y en solución de sulfatos y fosfatos 1X se observó una caída en la concentración de alrededor de un orden de magnitud durante los primeros $30 \mathrm{~d}$. Esta caída no se observó cuando se quintuplicó la concentración de las 

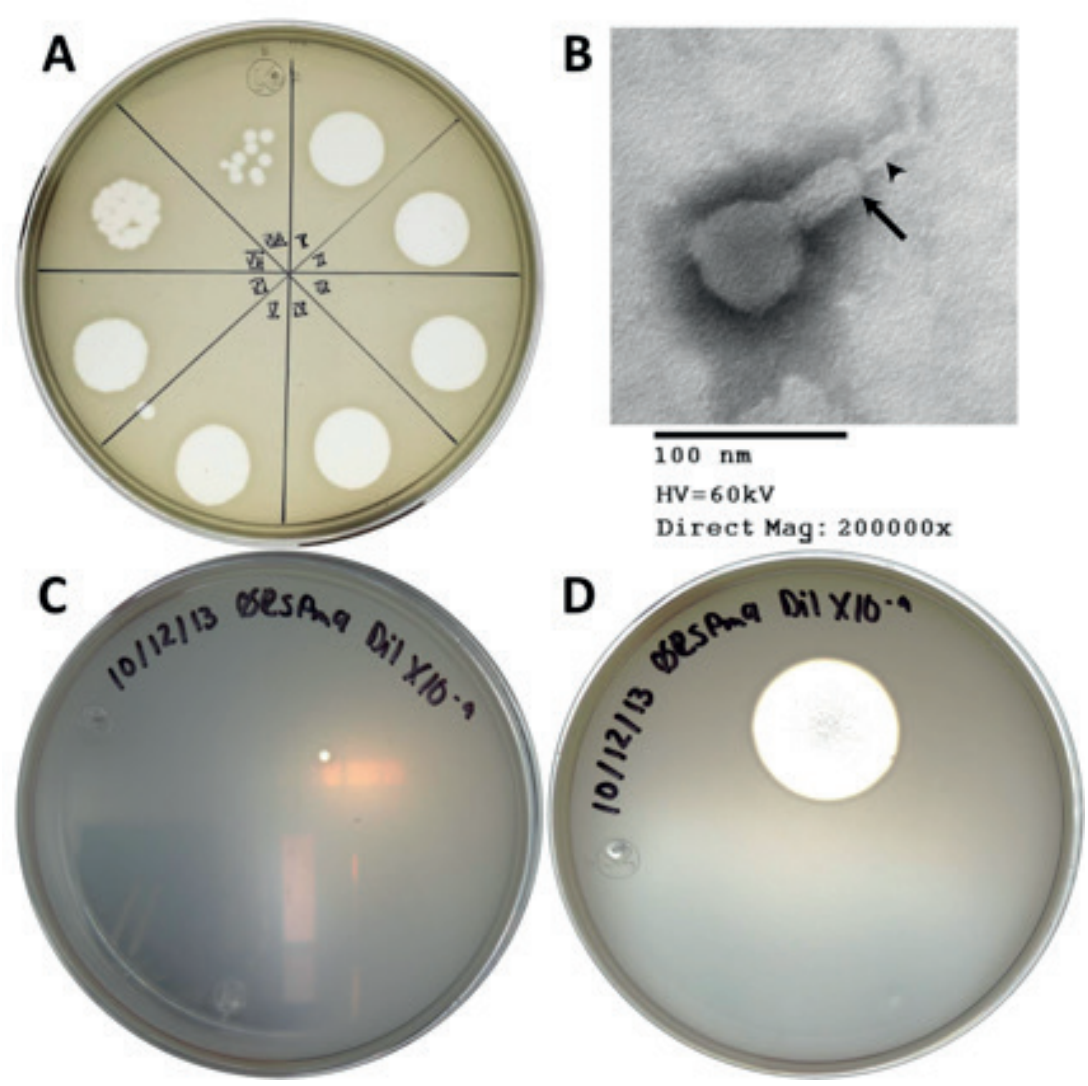

Figura 1. Placas de lisis y morfología microscópica del bacteriófago $\Phi$ RSP. A) Resultado de la prueba de detección de fagos en la muestra de agua analizada. Cada división corresponde a una dilución decimal I: $10^{-1}$, II: $10^{-2}$, III: $10^{-3}$, etc. En la dilución $10^{-8}$ (división VIII) se detectan 10 placas individuales. B) Imagen de la partícula fágica obtenida por microscopía electrónica de transmisión. C) y D) Misma placa de lisis a las 24 h y dos semanas de incubación, respectivamente.

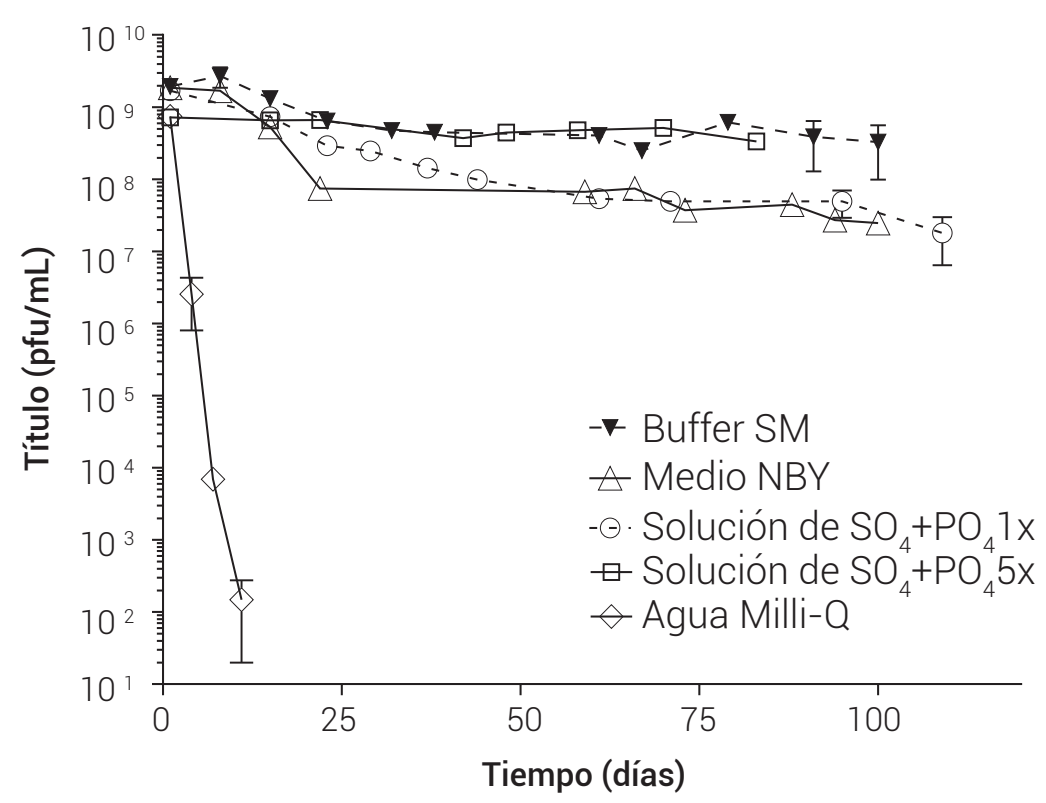

Figura 2. Estabilidad del bacteriófago $\Phi$ RSP en soluciones acuosas de diferente composición y en agua grado Milli-Q. El bacteriófago es más estable en la solución de sulfatos y fosfatos $5 \mathrm{X}$ y muy inestable en agua Milli-Q. 
sales en la solución de sulfatos y fosfatos (5X). En esta solución la concentración se mantuvo prácticamente sin cambios durante $83 \mathrm{~d}$. En el agua Milli-Q el fago fue muy inestable, no detectándose después de 20 d, lo que señala la importancia de las sales para estabilizar al bacteriófago. Estos resultados muestran que el bacteriófago $\Phi R S P$ es más estable en una solución de sulfatos y fosfatos, cuya composición y concentración de sales es similar a la utilizada en los cultivos de tomate hidropónico. Los intervalos de concentraciones de cada sal en las que el fago es estable son: $\mathrm{K}_{2} \mathrm{SO}_{4}$ de $0.27 \mathrm{~g} \mathrm{~L}^{-1}$ a $1.35 \mathrm{~g} \mathrm{~L}^{-1}$; $\mathrm{MgSO}_{4} \cdot 7 \mathrm{H}_{2} \mathrm{O}$ de $0.44 \mathrm{~g} \mathrm{~L}^{-1}$ a $2.20 \mathrm{~g} \mathrm{~L}^{-1} ; \mathrm{KH}_{2} \mathrm{PO}_{4^{\prime}} 0.14 \mathrm{~g} \mathrm{~L}^{-1} \mathrm{a}$ $0.70 \mathrm{~g} \mathrm{~L}^{-1}$, lo que abre la posibilidad de aplicarlo a través del sistema de riego automatizado.

\section{Estabilidad del bacteriófago $\Phi$ RSP a distintos valores de $\mathrm{pH}$}

Dado que el bacteriófago $\Phi$ RSP presentó la mayor estabilidad en la solución de sulfatos y fosfatos $5 X$, se evaluó su estabilidad a diferentes valores de $\mathrm{pH}$ en esta solución, como se describe en la metodología. El bacteriófago fue estable en un intervalo de $\mathrm{pH}$ de 4 a 11 (Figura 3). A valores de $\mathrm{pH}$ menores o iguales a 3, o mayores o iguales a 12, el fago no se detectó después de 1 h de exposición. Esto podría ser consecuencia de cambios proteicos conformacionales o de la distribución de cargas eléctricas de los residuos de aminoácidos que afectan la unión del fago con su receptor (Di Russo et al., 2012). El perfil de estabilidad frente al pH es característico de cada bacteriófago; en algunos casos los fagos son estables en un intervalo de $\mathrm{pH}, \mathrm{y}$ caen drásticamente fuera de éste (Jepson y March, 2004; Jin et al., 2012), mientras que en otros la estabilidad varía gradualmente y presenta un máximo a cierto valor de pH (Jin et al., 2012; Knezevic et al., 2011; Yang et al., 2010).

El perfil de estabilidad que presenta el bacteriófago ФRSP es muy similar al que se presenta en el bacteriófago KHP30 (Uchiyama et al., 2013); en ambos casos, la estabilidad se reduce drásticamente después de un valor de umbral. Estos resultados sugieren que el bacteriófago ФRSP será estable bajo las condiciones que se presentan en los cultivos de tomate, donde los productores de esta hortaliza utilizan soluciones con un pH cercano a la neutralidad, pero con frecuencia tienen que ajustar el pH de las soluciones nutritivas, lo que provoca ligeros cambios temporales en este parámetro.

\section{Efecto del bacteriófago $\Phi$ RSP sobre el crecimiento bacteriano}

Cuando el bacteriófago ФRSP se adicionó a cultivos líquidos de $R$. solanacearum que se encontraban al inicio de la fase de crecimiento exponencial se inhibió el crecimiento microbiano (Figura 4). Los perfiles de densidad óptica mostraron una reducción significativa del crecimiento bacteriano en presencia del bacteriófago y se anuló completamente el incremento en la densidad óptica a una $\mathrm{MOI}$ de $10^{-2}$. En las MOl's de $10^{-4}$ y $10^{-6}$ se formaron aglomerados de detritus celulares que generaban lecturas dispersas en la densidad óptica, estos aglomerados rápidamente sedimentaban cuando el tubo se dejaba en reposo. Se obtuvo un resultado similar a las tres multiplicidades de infección (MOl's) utilizadas $\left(10^{-2}, 10\right.$ ${ }^{4}, 10^{-6}$ ), lo que indica que el bacteriófago ejerció su efecto

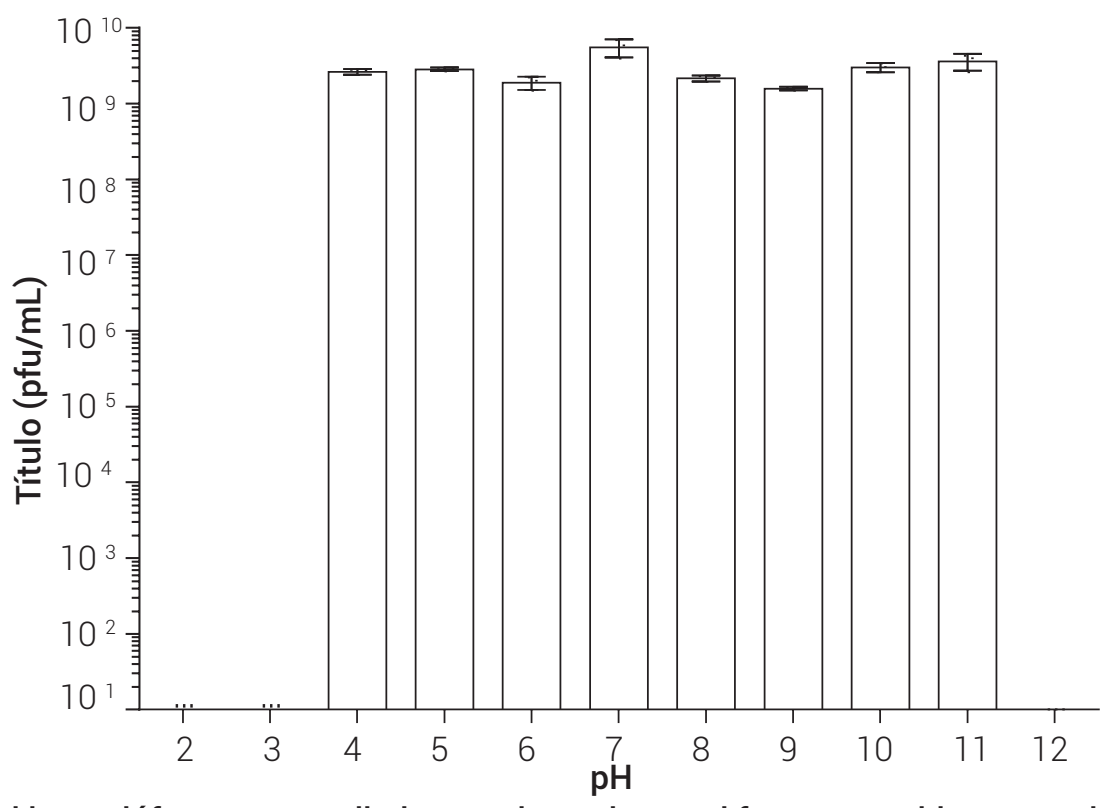

Figura 3. Estabilidad del bacteriófago $\Phi$ RSP a distintos valores de $\mathrm{pH}$. El fago es estable entre valores de pH de 4 a 11. 


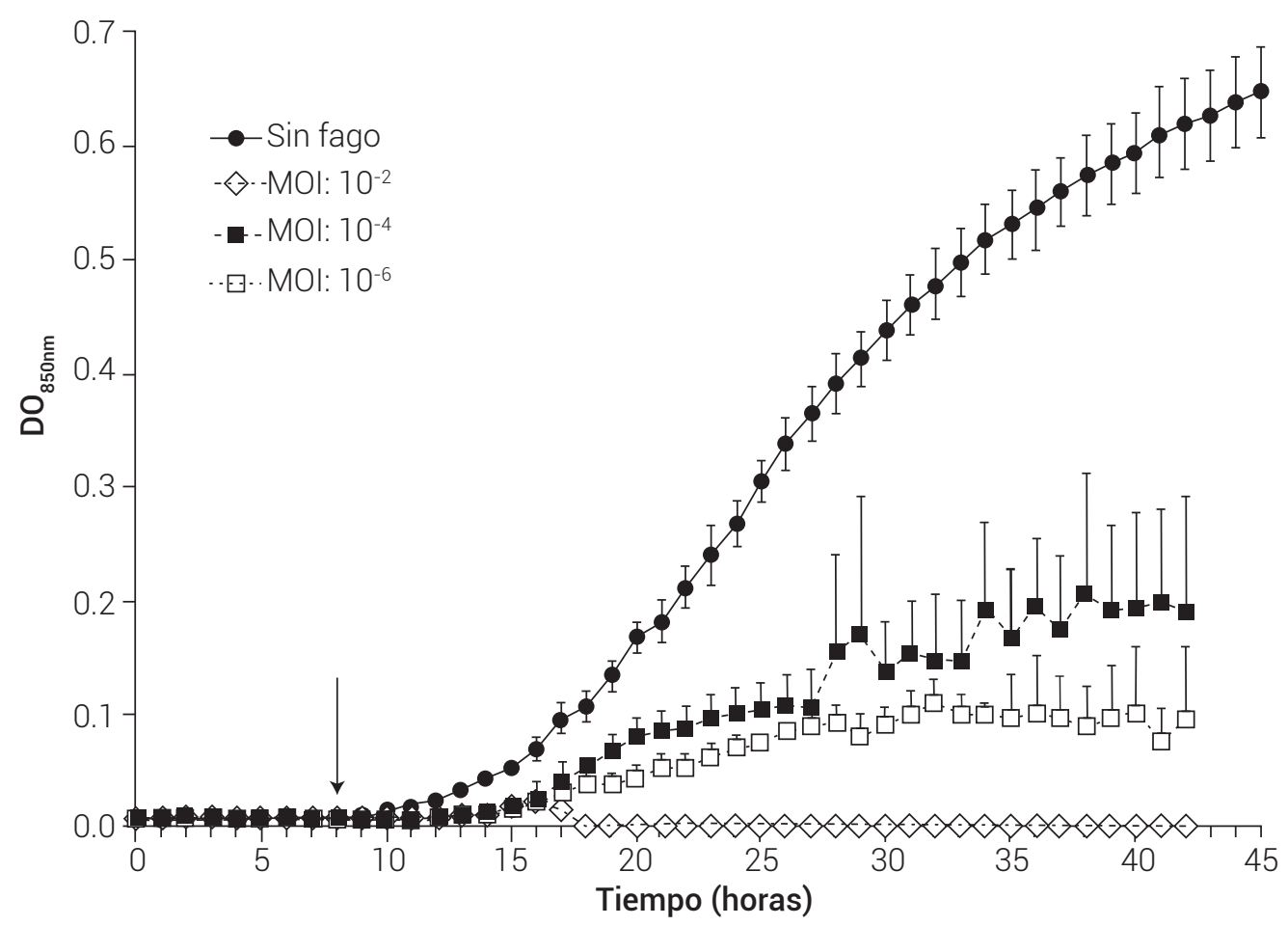

Figura 4. Efecto inhibitorio del bacteriófago $\Phi R S P$ sobre cultivos líquidos de $R$. solanacearum con diferentes multiplicidades de infección (MOl's). La flecha indica el punto en el que se adicionó el fago al cultivo. El bacteriófago impide el crecimiento bacteriano, aun bajo condiciones en las que se utiliza un bacteriófago por cada millón de bacterias.

lítico, incluso cuando se utilizó un fago por cada millón de bacterias presentes en el medio.

Para el caso de los experimentos en los que se utilizó una $\mathrm{MOI}$ de $10^{-2}$, se adicionaron $22 \mu \mathrm{L}\left(5.2 \times 10^{7}\right.$ fagos $)$ de una solución fágica de concentración $2.37 \times 10^{9}$ pfu's/ $\mathrm{mL}$, a $25 \mathrm{~mL}\left(5.2 \times 10^{9}\right.$ bacterias $)$ de una suspensión bacteriana de concentración $2.1 \times 10^{8} \mathrm{ufc} / \mathrm{mL}$. De esta forma, la concentración de fagos que ejerció el máximo efecto inhibitorio fue de $2.09 \times 10^{6} \mathrm{pfu} / \mathrm{s} / \mathrm{mL}$. Para el caso de la $\mathrm{MOI}$ de $10^{-6}$, se adicionaron $22 \mu \mathrm{L}\left(5.2 \times 10^{3}\right.$ fagos $)$ de una solución fágica de concentración $2.37 \times 10^{5} \mathrm{pfu}$ 's $/ \mathrm{mL}$, a la misma cantidad de bacterias. En este experimento la concentración fágica fue de 209 pfu's/mL.

En reportes previos se obtuvieron resultados similares en los que se utilizaron MOI's de 0.5 y 5.0 (Fujiwara et al., 2011) o de 0.1, 1.0 y 10 (Ma et al., 2018), valores muy elevados que podrían limitar el tratamiento con bacteriófagos a gran escala debido a la gran cantidad de fagos requeridos, lo que incrementaría los costos de producción. Recientemente se ha reportado que algunos bacteriófagos tienden a presentar un comportamiento lítico frente a uno lisogénico cuando las multiplicidades de infección son bajas, gracias a que existen sistemas de comunicación que permiten a los bacteriófagos censar su densidad poblacional (Erez et al., 2017). Los resultados muestran que la capacidad inhibitoria del fago $\Phi$ RSP se presenta en valores de $\mathrm{MOI}$ de $10^{-2}$ a $10^{-6}$, lo que resulta de utilidad práctica, ya que bajas concentraciones del fago podrían tener un efecto protector, lo que reduciría los costos del tratamiento con este tipo de agentes de biocontrol.

Se ha secuenciado el genoma completo de este bacteriófago (GenBank MH252365) y no se han encontrado genes que codifiquen para factores de virulencia conocidos, tampoco se ha detectado un módulo de lisogenia funcional; estas características genómicas concuerdan con el comportamiento lítico que presenta in vitro. Adicionalmente, se ha evaluado al fago frente a 18 cepas bacterianas aisladas de la rizosfera de plantas de tomate, así como frente a seis cepas de $R$. solanacearum aisladas en Morelos y el Estado de México en diferentes años, en las que se observó actividad lítica frente a todas las cepas del fitopatógeno, pero hacia ninguno de los aislamientos bacterianos de la rizosfera.

\section{CONCLUSIONES}

El bacteriófago QRSP presenta características fisicoquímicas y biológicas que lo señalan como un potencial agente de biocontrol para combatir la marchitez 
bacteriana causada por R. solanacearum en tomate. Este bacteriófago es estable en soluciones salinas con una composición química de sulfatos y fosfatos similar a las que se utilizan en las soluciones nutritivas de los cultivos de tomate, así como a valores de $\mathrm{pH}$ en un intervalo de $4.0 \mathrm{a}$ 11.0; además, es capaz de difundir en ambientes similares a los recubrimientos bacterianos e inhibir el crecimiento de $R$. solanacearum en cultivos líquidos a multiplicidades de infección de $10^{-2}, 10^{-4}$ y $10^{-6}$. Estas características sugieren que durante su aplicación en campo permanecerá viable y limitará el crecimiento de $R$. solanacearum, aún cuando se aplique a bajas concentraciones.

\section{AGRADECIMIENTOS}

Los autores agradecen el apoyo otorgado por CONACyT a través del fideicomiso FOMIX-Morelos, con el proyecto MOR-2010-C01-148777.

\section{BIBLIOGRAFÍA}

Abedon S. T. and J. Yin (2009) Bacteriophage plaques: theory and analysis. In: Bacteriophages. Methods in Molecular Biology 501. Vol. 1: Isolation, Characterization and Interactions. M. R. J. Clokie and A. M. Kropinski (eds.). Humana Press. New York. pp:161-174, https://doi.org/10.1007/978-1-60327-164-6_17

Ackermann H. W. (2011) Bacteriophage taxonomy. Microbiology Australia 32:90-94.

Addy H. S., A. Askora, T. Kawasaki, M. Fujie and T. Yamada (2012a) The filamentous phage PRSS1 enhances virulence of phytopathogenic Ralstonia solanacearum on tomato. Phytopathology 102:244-251, https://doi.org/10.1094/ PHYTO-10-11-0277

Addy H. S., A. Askora, T. Kawasaki, M. Fujie and T. Yamada (2012b) Loss of virulence of the phytopathogen Ralstonia solanacearum through infection by $\varphi$ RSM filamentous phages. Phytopathology 102:469-477, https://doi.org/10.1094/PHYTO-11-11-0319-R

Addy H. S., A. Askora, T. Kawasaki, M. Fujie and T. Yamada (2012c) Utilization of filamentous phage $\Phi R S M 3$ to control bacterial wilt caused by Ralstonia solanacearum. Plant Disease 96:1204-1209, https:// doi.org/10.1094/PDIS-12-11-1023-RE

Bae J. Y., J. Wu, H. J. Lee, E. J. Jo, S. Murugaiyan, E. Chung and S. W. Lee (2012) Biocontrol potential of a lytic bacteriophage PE204 against bacterial wilt of tomato. Journal of Microbiology and Biotechnology 22:1613-1620, https://doi.org/10.4014/ jmb. 1208.08072

Bhunchoth A., N. Phironrit, C. Leksomboon, O. Chatchawankanphanich, S. Kotera, E. Narulita, T. Kawasaki, M. Fujie and T. Yamada (2015) Isolation of Ralstonia solanacearum-infecting bacteriophages from tomato fields in Chiang Mai, Thailand, and their experimental use as biocontrol agents. Journal of Applied Microbiology 118:1023-1033, https://doi.org/10.1111/jam.12763

Di Russo N. V., D. A. Estrin, M. A. Martí and A. E. Roitberg (2012) pHdependent conformational changes in proteins and their effect on experimental $\mathrm{pK}_{2} \mathrm{~s}$ : the case of nitrophorin 4. PLOS Computational Biology 8:e1002761, https://doi.org/10.1371/ journal.pcbi. 1002761

Economou V. and P. Gousia (2015) Agriculture and food animals as a source of antimicrobial-resistant bacteria. Infection and Drug Resistance 8:49-61, https://doi.org/10.2147/IDR.S55778

Erez Z., I. Steinberger-Levy, M. Shamir, S. Doron, A. Stokar-Avihail, Y. Peleg, S. Malamed, A. Leavitt, A. Savidor, S. Albeck, G. Amitai and R. Sorek (2017) Communication between viruses guides lysis-lysogeny decisions. Nature 541:488-493, https://doi.org/10.1038/ nature21049
Evtushenko L. I. and M. Takeuchi (2006) The family microbacteriaceae In: The Prokaryotes. Third Edition. Vol. 3. Archaea. Bacteria: Firmicutes, Actinomycetes. M. Dworkin, S. Falkow, E. Rosenberg, K. H. Schleifer and E. Stackebrandt (eds.). Springer. Singapore. pp:1020-1098, https://doi.org/10.1007/0-387-30743-5_43

Falkowski P. G., T. Fenchel and E. F. Delong (2008) The microbial engines that drive Earth's biogeochemical cycles. Science 320:10341039, https://doi.org/10.1126/science.1153213

Frampton R. A., A. R. Pitman and P. C. Fineran (2012) Advances in bacteriophage-mediated control of plant pathogens. International Journal of Microbiology 2012:326452, https://doi. org/10.1155/2012/326452

Fujiwara A., M. Fujisawa, R. Hamasaki, T. Kawasaki, M. Fujie and T. Yamada (2011) Biocontrol of Ralstonia solanacearum by treatment with lytic bacteriophages. Applied and Environmental Microbiology 77:4155-4162, https://doi.org/10.1128/AEM.02847-10

Gallet R., S. Kannoly and I. N. Wang (2011) Effects of bacteriophage traits on plaque formation. BMC Microbiology 11:181, https://doi org/10.1186/1471-2180-11-181

Gallet R., Y. Shao and I. N. Wang (2009) High adsorption rate is detrimental to bacteriophage fitness in a biofilm-like environment. BMC Evolutionary Biology 9:241, https://doi.org/10.1186/14712148-9-241

Hayward A. C. (1991) Biology and epidemiology of bacterial wilt caused by Pseudomonas solanacearum. Annual Review of Phytopathology 29:65-87, https://doi.org/10.1146/annurev. py.29.090191.000433

Hernández-Romano J., S. Ramírez-Rojas and C. J. Ydrac-Morales (2012) First report of Ralstonia solanacearum causing tomato bacterial wilt in Mexico. New Disease Reports 26:22, https://doi.org/10.5197 /j.2044-0588.2012.026.022

Jassim S. A. A. and R. G. Limoges (2014) Natural solution to antibiotic resistance: bacteriophages 'The Living Drugs'. World Journal of Microbiology and Biotechnology 30:2153-2170, https://doi. org/10.1007/s11274-014-1655-7

Jepson C. D. and J. B. March (2004) Bacteriophage lambda is a highly stable DNA vaccine delivery vehicle. Vaccine 22:2413-2419, https://doi.org/10.1016/j.vaccine.2003.11.065

Jin J., Z. J. Li, S. W. Wang, S. M. Wang, D. H. Huang, Y. H. Li, Y. Y. Ma, J. Wang, F. Liu, X. D. Chen, G. X. Li, X. T. Wang, Z. Q. Wang and G. Q. Zhao (2012) Isolation and characterization of ZZ1, a novel lytic phage that infects Acinetobacter baumannii clinical isolates. BMC Microbiology 12:156, https://doi.org/10.1186/1471-2180-12156

Jones J. B., L. E. Jackson, B. Balogh, A. Obradovic, F. B. Iriarte and M. T. Momol (2007) Bacteriophages for plant disease control. Annual Review of Phytopathology 45:245-262, https://doi.org/10.1146/ annurev.phyto.45.062806.094411

Kalpage M. D. and D. M. De Costa (2014) Isolation of bacteriophages and determination of their efficiency in controlling Ralstonia solanacearum causing bacterial wilt of tomato. Tropical Agricultural Research 26:140-151, https://doi.org/10.4038/tar. v26i1.8079

Knezevic P., D. Obreht, S. Curcin, M. Petrusic, V. Aleksic, R. Kostanjsek and 0. Petrovic (2011) Phages of Pseudomonas aeruginosa: response to environmental factors and in vitro ability to inhibit bacterial growth and biofilm formation. Journal of Applied Microbiology 111:245-254, https://doi.org/10.1111/j.13652672.2011.05043.x

Kropinski A. M., A. Mazzocco, T. E. Waddell, E. Lingohr and R. P. Johnson (2009) Enumeration of bacteriophages by double agar overlay plaque assay. In: Bacteriophages. Methods in Molecular Biology 501. Vol. 1. Isolation, Characterization and Interactions M. R. J. Clokie and A. M. Kropinski (eds.). Humana Press. New York. pp:69-76, https://doi.org/10.1007/978-1-60327-164-6_7

López C. O., J. León F., M. Jiménez E. and C. Chaidez Q. (2009) Detección y resistencia a antibióticos de Escherichia coli y Salmonella en agua y suelo agrícola. Revista Fitotecnia Mexicana 32:119-126.

Ma L., S. I. Green, B. W. Trautner, R. F. Ramig and A. W. Maresso (2018) Metals enhance the killing of bacteria by bacteriophage in human blood. Scientific Reports 8:2326, https://doi.org/10.1038/ s41598-018-20698-2 
Mansfield J., S. Genin, S. Magori, V. Citovsky, M. Sriariyanum, P. Ronald, M. Dow, V. Verdier, S. V. Beer, M. A. Machado, I. Toth, G. Salmond and G. D. Foster (2012) Top 10 plant pathogenic bacteria in molecular plant pathology. Molecular Plant Pathology 13:614-629, https:// doi.org/10.1111/j.1364-3703.2012.00804.x

McManus P. S., V. O. Stockwell, G. W. Sundin and A. L. Jones (2002) Antibiotic use in plant agriculture. Annual Review of Phytopathology 40:443-465, https://doi.org/10.1146/annurev. phyto.40.120301.093927

Obrador-Sánchez J. A., M. Tzec-Simá, I. Higuera-Ciapara and B. Canto-Canché (2017) Genetic diversity of Ralstonia solanacearum strains from Mexico associated with Moko disease. European Journal of Plant Pathology 149:817-830, https://doi.org/10.1007/ s10658-017-1228-3

Perea S. J. M., R. S. García E., R. Allende M., J. A. Carrillo F., J. León F., B. Valdez T. y F. S. M. López S. (2011) Identificación de razas y biovares de Ralstonia solanacearum aisladas de plantas de tomate. Revista Mexicana de Fitopatología 29:98-108.

Sharma S. B., R. Z. Sayyed, M. H. Trivedi and T. A. Gobi (2013) Phosphate solubilizing microbes: sustainable approach for managing phosphorus deficiency in agricultural soils. SpringerPlus 2:587, https://doi.org/10.1186/2193-1801-2-587

Stockwell V. O. and B. Duffy (2012) Use of antibiotics in plant agriculture. Revue Scientifique et Technique 31:199-210.
Sundin G. W., L. F. Castiblanco, X. Yuan, Q. Zeng and C. H. Yang (2016) Bacterial disease management: challenges, experience, innovation and future prospects. Molecular Plant Pathology 17:1506-1518, https://doi.org/10.1111/mpp.12436

Thiele-Bruhn S. (2003) Pharmaceutical antibiotic compounds in soils - a review. Journal of Plant Nutrition and Soil Science 166:145-167, https://doi.org/10.1002/jpln.200390023

Uchiyama J., H. Takeuchi, S. I. Kato, K. Gamoh, I. Takemura-Uchiyama, T. Ujihara, M. Daibata and S. Matsuzaki (2013) Characterization of Helicobacter pylori bacteriophage KHP30. Applied and Environmental Microbiology 79:3176-3184, https://doi. org/10.1128/AEM.03530-12

Yang H., L. Liang, S. Lin and S. Jia (2010) Isolation and characterization of a virulent bacteriophage AB1 of Acinetobacter baumannii. BMC Microbiology 10:131, https://doi.org/10.1186/1471-2180-10131

You Y. and E. K. Silbergeld (2014) Learning from agriculture: understanding low-dose antimicrobials as drivers of resistome expansion Frontiers in Microbiology 5:284, https://doi.org/10.3389/ fmicb. 2014.00284

Żaczek M., B. Weber-Dąbrowska and A. Górski (2015) Phages in the global fruit and vegetable industry. Journal of Applied Microbiology 118:537-556, https://doi.org/10.1111/jam.12700 